\title{
Catarata em pequenos animais: classificação e tratamento
}

CORRESPONDENCE TO: Josd Lutz Lau Departamento de Clinica - Cirurgia Voterninerie

Faculdade de Ciencias Agrdrias o

Voterindina da UNESP

Rodovia Carios Tonannl, $\mathrm{km} 5$

14870-000 - Jaboticabal - SP - Breal

-mail: laus//@lab.000ues. ans.br

1 - Universidade Federal do

Paraná, Curtiba - PR

2 - Departamento de Clínica $\theta$

Cirurgla Veterinária - FCAV.

UNESP - Jaboticabal - SP

3. Médico veterinário autónomo

\section{RESUMO}

Por catarata, entende-se qualquer opacidade presente no cristalino, cápsula do cristalino ou ambos. As opacidades podem variar quanto ao tamanho, localização, forma e velocidade de progressão. Através da biomicroscopia com lâmpada de fenda é possível examiná-las com precisāo, determinando sua localizaçào e peculiaridades, propiciando um diagnóstico acurado e seguro. Devido à origem e aparência variáveis, muitos métodos de classificação têm sido utilizados. Classificação quanto à etiologia, grau de maturidade, localização e idade do paciente sāo apresentados nesta revisão. A remoçāo cirúrgica é a única forma de terapia efetiva para a enfermidade. Dentre as técnicas existentes, destaca-se a facoemulsificaçāo endocapsular, por seus melhores resultados, nāo obstante seus altos custos, comparativamente às facectomias intra e extracapsulares clássicas.

UNITERMOS: Catarata; Facoemulsificação; Cães; Gatos.

\section{INTRODUÇĀO}

D enomina-se catarata qualquer opacificação da cápsula. córtex ou núcleo do cristalino (Rubin ${ }^{15}, 1989$ ). Estas opacificaçōes podem apresentar diferentes padrōes morfológicos que invariavelmente se relacionam com o aspecto etiológico. Dentro de um exame oftalmológico, podem-se determinar a localizaçāo e as características das opacificações acuradamente, por meio do uso de um biomicroscópio com lâmpada de fenda.

A cirurgia é o método mais eficiente de tratamento da catarata quando se objetiva a restauração completa e segura da visão do paciente $e^{5,6,911.12}$. O método cirúrgico sofreu um processo evolutivo considerável durante os últimos anos. graças ao advento da técnica de facoemulsificação endocapsular e ao grande desenvolvimento tecnológico da produção dos materiais empregados nesta técnica cirúrgica (Nasisse et al. ${ }^{11}, 1991$ ).

\section{CLASSIFICAÇÃO}

As cataratas podem ser classificadas quanto a quatro aspectos diferentes: a etiologia, a idade do paciente na ocasiāo do aparecimento da catarata, a localizaçāo da opacificaçāo e o estágio de maturação no qual a catarata se encontra.

\section{Etiologia}

As alteraçōes cataractogênicas que o cristalino pode sofrer de modo geral são: alteraçōes no equilíbrio eletrolítico e por extensão do conteúdo aquoso do cristalino, alteraçōes das membranas das células epiteliais cubóides do cristalino devido a inflamaçōes ou por ação de radicais livres, alteraçōes das fibras e das células do cristalino por ação mecânica e diversas alteraçōes durante a embriogênese e no desenvolvimento como a persistência da membrana pupilar ou a persistência da artéria hialóide (Strande et al. ${ }^{18}, 1988$; English", 1992).

A grande maioria das cataratas diagnosticadas em câes é de caráter hereditário. As cataratas hereditárias sāo invariavelmente bilaterais, mas raramente são simétricas quanto à opacificação. Nos gatos, as cataratas diagnosticadas são mais comumente associadas à uveítes, cristalinos luxados e outras doenças oculares (Dziezvc ${ }^{\text {th }}$ 1990).

As condições clínicas desencadeantes de cataratas incluem, mais comumente, diabete melitus (hiperglicemia), galactosemia, hipocalcemia, inflamação de estruturas oculares internas (uveíte), tirosinemia. choque elétrico, trauma, exposição a radiação, contato com substâncias tóxicas (esteróides, anticolinesterásicos, fenotiazínicos e outros), tumores intra-oculares (melanoma maligno do corpo ciliar), cuprismo e dermatite atópica $a^{4,8.16,17,18}$.

Existe uma forte correlaçāo positiva na manifestação da atrofia retiniana e da catarata, principamente em cảes das raças Poodle, Yorkshire Terrier e Bichon Frisé (Rubin's. 1989: Whitley et al. $.^{19}, 1993$ ).

Alguns autores utilizam uma classificação baseada na causa da catarata em algumas formas particulares de opacificação. Por exemplo, aquelas cataratas ocasionadas pelo desequilíbrio do conteúdo aquoso do cristalino em vigência de um estado hiperglicêmico podem ser denominadas cataratas dos diabéticos ou sugar cataracts (Roversi; Giavinit"; 1992). A catarata, nos seus estágios iniciais, pode representar um dos primeiros sinais clínicos reconhecíveis em pacientes diabéticos (English $\left.{ }^{8}, 1992\right)$. A catarata resultante de uveite pode ser denominada de catarata complicata. 


\section{CLASSIFICAÇÃo QUANTO À IDADE DO PACIENTE}

\section{Cataratas congênitas}

As opacificaçōes que já estão presentes por ocasião do nascimento do paciente são consideradas cataratas congênitas. Este tipo de catarata pode ser essencialmente de caráter hereditário, como é comum nos cães da raça Schnauzer, Pastor Alemão e Cocker Spaniel, ou pode ser associado a uma anormalidade sistêmica sofrida pela mãe durante a gestação. Se este distúrbio sistêmico ocorrer no início da gestação, as fibras primárias do cristalino são afetadas, resultando em uma opacificação nuclear do cristalino (Barros ${ }^{1}, 1989$; Carastro ${ }^{3}, 1993$ ).

\section{Cataratas juvenis}

As cataratas juvenis são classificadas por English ${ }^{8}$ (1992) como aquelas que se desenvolvem em pacientes que possuam menos de dois anos de idade. Tal distinção é um tanto arbitrária, uma vez que se observam cataratas notadamente juvenis em animais com idade superior a dois anos. Estas cataratas sāo geralmente de caráter hereditário e sảo comumente diagnosticadas em cães das raças Afghan Hound, Cocker Spaniel, Golden Retrivier, Poodle, Kuvaz, entre outros (Rubin ${ }^{15}$, 1989; Carastro ${ }^{3}$, 1993).

\section{Cataratas dos adultos}

Muitos autores sugerem que as cataratas dos adultos sejam as opacificações que se desenvolvem em pacientes com dois a seis anos de idade. Este tipo de catarata é comum nos cães da raça Cocker Spaniel (Rubin ${ }^{15}$, 1989; English $\left.{ }^{8}, 1992\right)$.

\section{Cataratas senis}

As cataratas que se desenvolvem em pacientes com idade avançada são extremamente comuns nos cães. São consideradas como cataratas senis aquelas que se desenvolvem em pacientes mais velhos do que seis anos de idade (Dziezyc $\left.{ }^{6}, 1990\right)$.

\section{CLASSIFICAÇÃO QUANTO À LOCALIZAÇÃO DA OPACIFICAÇĀO}

\section{Cataratas capsulares}

As opacificaçōes localizadas na cápsula anterior ou posterior do cristalino são denominadas cataratas capsulares. A causa mais freqüente deste tipo de catarata é a ruptura traumática do globo ocular, ocasionada comumente em cães por arranhadura de gatos. As opacificaçōes da cápsula posterior podem ser ocasionadas principalmente por persistência do vítreo primário (persistência da artéria hialóide). Normalmente não são progressivas (Carastro $\left.{ }^{3}, 1993\right)$.

\section{Cataratas subcapsulares}

As cataratas subcapsulares são aquelas opacificaçōes localizadas imediatamente abaixo da cápsula anterior ou posterior do cristalino. Estas cataratas geralmente são congênitas ou podem ocorrer após traumas ou contato com substâncias tóxicas. Quando as cataratas subcapsulares ou capsulares possuírem uma localização mais central podem também ser denominadas cataratas polares (English ${ }^{8}, 1992 ;$ Carastro $\left.^{3}, 1993\right)$.

As cataratas subcapsulares posteriores são mais bem examinadas através da retroiluminaçāo contra o reflexo do fundo de olho. Este tipo de catarata comumente está associado com uveítes, uso prolongado de esteróides e diabetes. Geralmente, nos humanos, esta forma de catarata ocorre em pacientes adultos ou idosos (Cullon; Chang', 1994).

\section{Cataratas corticais}

Sảo denominadas cataratas corticais aquelas opacificaçōes que se localizam no córtex do cristalino. São bastante comuns nos cães e normalmente estão associadas com diabete melitus, atrofia retiniana progressiva e exposição a toxinas. Normalmente estas cataratas sāo progressivas (Carastro $\left.{ }^{3}, 1993\right)$.

\section{Cataratas nucleares}

São denominadas cataratas nucleares aquelas opacificaçōes localizadas no núcleo do cristalino. Estas cataratas geralmente são congênitas e nāo são acompanhadas de deficits visuais. $\mathrm{Na}$ grande maioria dos casos são bilaterais e não progressivas (Carastro $\left.{ }^{3}, 1993\right)$.

As cataratas nucleares verdadeiras são comumente confundidas com um fenômeno senil que leva a uma ligeira opacificação no núcleo do cristalino, denominado esclerose nuclear do cristalino. Este fenômeno senil, muito comum nos cães, ocorre devido a um aumento na proporção das proteínas insolúveis do cristalino (proteínas albuminóides) em relaçāo às proteínas solúveis (proteinas cristalinas) (English $\left.{ }^{8}, 1992\right)$, ocasionando assim uma perda da elasticidade do cristalino. Esta condição clínica assemelha-se a presbiopia dos pacientes humanos idosos. Em animais idosos, a distinção entre a esclerose nuclear e a catarata incipiente pode ser difícil (Slatter $\left.{ }^{16}, 1990\right)$ (Fig. 1a).

\section{Cataratas equatoriais}

As cataratas equatoriais sāo aquelas localizadas na periferia do cristalino. Para que se possam vê-las, há a necessidade de se promover a midríase completa. Normalmente são progressivas (English $\left.{ }^{8}, 1992\right)$.

\section{CLASSIFICAÇĀO QUANTO AO ESTÁGIO DE MATURAÇĀO}

O conhecimento da metodologia adotada para a classificação das cataratas quanto ao estágio de maturidade é muito importante para que possamos determinar a velocidade da evolução das opacificaçōes do cristalino. Esta classificação usa como parâmetros o grau de opacificação do cristalino $(0,0 \%$ a 100,0\%), a possibilidade ou a impossibilidade de se observar o fundo de olho e o reflexo tapetal, a presença de pequenos fragmentos protéicos do cristalino atravessando a cápsula anterior e o deslocamento do núcleo em direçāo ventral dentro da cápsula (Neumann ${ }^{13}$, 1991; English $\left.{ }^{8}, 1992\right)$.

\section{Catarata incipiente}

Nesta fase, a opacificaçāo do cristalino dá-se na forma de pequenos pontos ou vacúolos no córtex ou no núcleo do cristalino. $O$ paciente não demonstra comprometimento visual algum. $O$ grau de opacificação do cristalino afetado em relação a um cristalino normal é menor do que 10,0\% (Carastro ${ }^{3}, 1993$; Whitley et al. $\left.{ }^{19}, 1993\right)$. Muitas vezes, o grau de opacificaçăo é mínimo e 
freqüentemente é observado em cristalino subluxados ou luxados, muito embora uma eventual degeneração endotelial conjunta possa confundir o examinador (Fig. Ib).

\section{Catarata imatura}

Este estágio é provavelmente o mais abrangente desta classificação, pois o grau de opacificação do cristalino neste caso pode variar de $10,0 \%$ até $80,0 \%$, tornando a denominação de catarata imatura um pouco arbitrária. No entanto, existem alguns parâmetros que são característicos da catarata imatura. $\mathrm{O}$ aspecto "inchado" que o cristalino pode apresentar, devido ao aumento de tamanho ocasionado pela embebiçāo das fibras do córtex por fluido, é característico de catarata imatura. Quando observam este fenômeno, alguns autores podem utilizar o termo catarata intumescente, que é uma subclassificação de catarata imatura. $\mathrm{O}$ paciente pode ou não apresentar um comprometimento visual e o reflexo tapetal ainda pode ser observado ${ }^{3,819}$ (Fig. 1c).

\section{Catarata madura}

A catarata é classificada como madura quando a opacificação envolve quase toda a lente e impede que o reflexo tapetal seja apreciado. $\mathrm{O}$ aspecto da opacificação normalmente é uniforme e esbranquiçado, também chamado de opacificação leitosa. Existe um grande comprometimento da acuidade visual do paciente. Nesta fase, o cristalino apresenta um grau de opacificação maior do que $80,0 \%$ em relação a um cristalino normal ${ }^{3,8,13,19}$ (Fig. 1d).

\section{Catarata hipermatura}

Nesta fase evolutiva, as fibras do córtex do cristalino completamente opaco começam a passar por um processo de liquefaçāo. A difusão destas massas liquefeitas do cristalino para a câmara anterior e posterior pode gerar um processo inflamatório na íris e no corpo ciliar, chamado de iridociclite facolítica, uveíte faco-anafilática, uveíte facogênica ou uveíte lente-induzida. Ocasionalmente. pode-se observar a presença de cristais no interior do cristalino.

Devido à liquefação do córtex do cristalino, o núcleo pode mover-se ventralmente dentro da cápsula por ação da gravidade. Quando este fenômeno for observado, pode-se classificar a catarata como Morgagniana, que corresponde a uma subclasse de catarata hipermatura ${ }^{3.14,19}$ (Figs. 1e; 1f).

\section{TÉCNICAS CIRÚRGICAS}

\section{Consideraçōes pré-operatórias}

Alguns pontos importantes devem ser considerados antes de selecionar um paciente para a realização de cirurgia de extração de catarata. $O$ tratamento cirúrgico não é indicado para pacientes com qualquer tipo de ceratite nāo tratada, distrofia retiniana, catarata secundária à uveíte ou ângulo de drenagem comprometido.

Todo paciente que possuir catarata cujo grau de opacificaçāo impossibilite a realização do exame de fundo de olho, além de um exame oftálmico completo, deve ser submetido a um eletrorretinograma (ERG) para aferiçāo da viabilidade eletrofisiológica da retina, para excluir os pacientes portadores de atrofia de retina e, em alguns casos, a uma ultra-sonografia (Dziezyc $^{\wedge}, 1990 ;$ Nasisse $\left.^{10}, 1995\right)$, para que se possam excluir pacientes portadores de descolamento de retina.

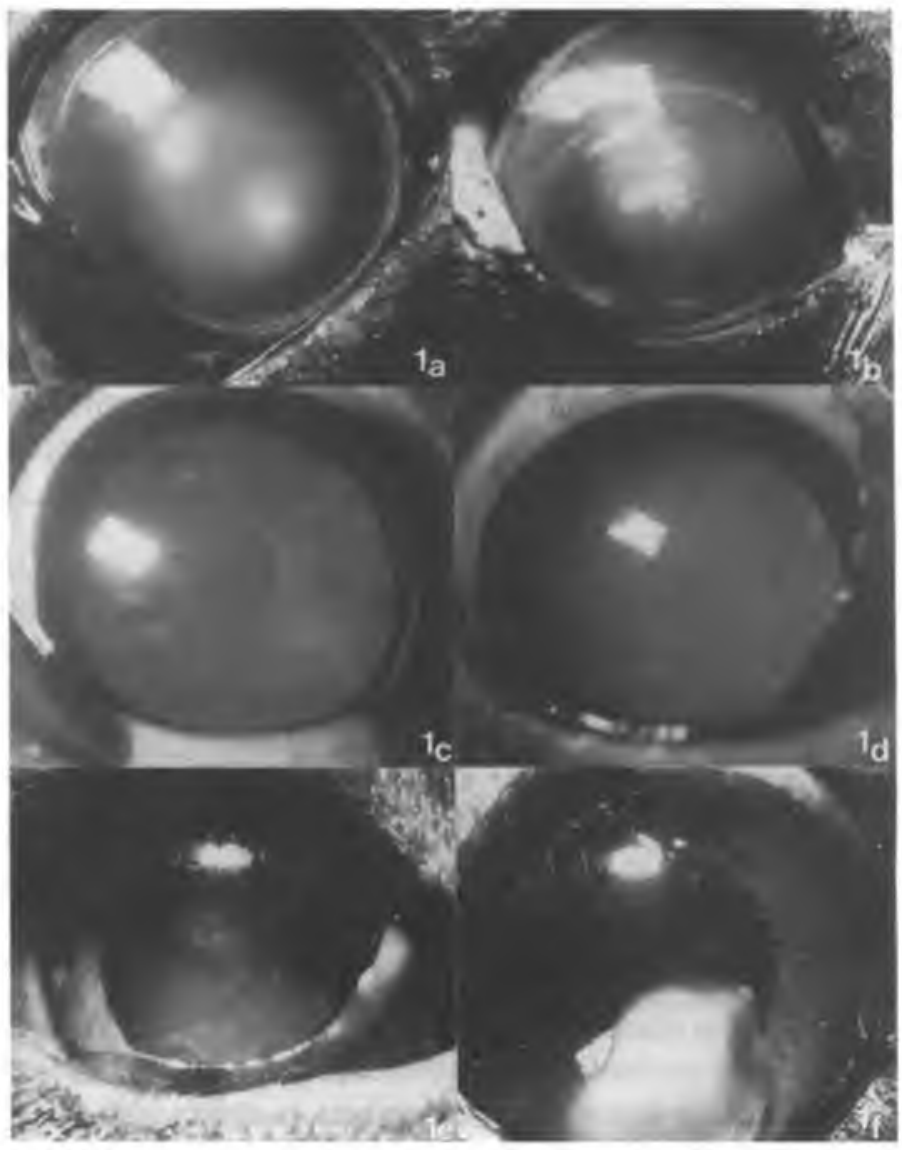

Figura 1

Figura la - Esclerose nuclear do cristalino.

Figura 10 - Luxação anterior do cristalino com presença de catarato incipiente. Notar a presença de degeneraçāo endotelíal, com opacificaçōo, devido ao contato do cristalino no endotélio da cómea. Figura lc - Catarata imaturo. Notar a presença de vacúolos no córtex do cristalino e seu aspecto "ingurgitado"

Figura ld - Catarata madura. Notar a opacificaçāo geral e uniforme do cristalino, dando um aspecto "leitoso" ao mesmo.

Figura le - Catarata hipermatura em processo de liquefaçōo protéica das fibras lenticulares.

Figura if - Catorata hipermatura em processo de reabsorçōo. Notar a localizaçāo em câmara anterior.

Geralmente, os pacientes que apresentam cataratas hipermaturas têm chances menores de sucesso pós-cirúrgico, porque têm maior probabilidade de apresentar, em maior ou menor grau, uveíte facogênica, descolamento de retina e opacificação da cápsula posterior do cristalino (Nasisse $\left.{ }^{10}, 1995\right)$. Portanto, a seleção de um paciente com catarata hipermatura para a cirurgia deve ser muito criteriosa. Sempre que possível, deve-se lançar mão de testes para examinar a viabilidade retiniana no exame pré-operatório.

A úvea do homem responde de maneira diferente da úvea dos cães ao trauma cirúrgico, observando-se nos últimos, um grau maior de iridociclite pós-cirúrgica e, conseqüentemente, de suas complicaçōes. Considera-se que a úvea do cão possui uma barreira hemato-ocular mais frágil, comparativamente ao paciente humano (Nasisse $\left.^{10}, 1995\right)$. Como resultado, qualquer colapso prolongado da câmara anterior resulta em queda crítica da pressão intra-ocular, 
que é acompanhada pela entrada de proteína e fibrina a partir dos vasos para a câmara anterior (Nasisse' 1995 ). Conseqüentemente. ocorre também com mais freqüência a seclusão pupilar póscirúrgica en cảes (Nasisse ${ }^{11 !}, 1995$ ).

\section{Extraçāo intracapsular de catarata}

Este método consiste na remoçảo do córtex e núcleo do cristalino juntamente com cápsula intacta, através de uma incisão extensa da córnea ( 17 a 22 milímetros).

Problemas da técnica: linha de incisão extensa, prolapso do corpo vítreo, descolamento de retina no pós-operatório, hifema por hemorragias coroidais, maior risco de deiscência dos pontos e uveíte pós-cirúrgica intensa.

Esta técnica cirúrgica é reservada a pacientes com luxação de cristalino e nāo deve ser aplicada em cirurgias cletivas de extraçāo de catarata (Dziez.yc', 199()).

\section{Extração ext racapsular de catarata}

Nesta técnica cirúrgica, a cápsula anterior é removida. Após isso, remove-se o córtex e o núcleo do cristalino, procurando deixar a cápsula posterior intacta (Dziezyct, $1 \%(0)$ ). Existem inúmeras variaçōes desta técnica, como, por exemplo, a técnica de discissão com aspiração/irrigação. Após a remoçẫo do núcleo do cristalino, podem-se utilizar fluidos heparinizados e uma cânula de irrigação/ aspiraçăo para a remoçāo dos fragmentos lenticulares periféricos. Estas variaçōes da técnica geralmente promovem resultados melhores no pós-operatório do que a técnica convencional simples. A técnica extracapsular apresenta resultados muito mais satisfatórios do que a extração intracapsular, chegando a atingir a taxa de sucesso cirúrgico de 87,5\% no Brasil para Barros ${ }^{2}$ (1990), mas ainda apresenta alguns problemas, como incisão extensa da córnca, uvé́te pós-operatória tardia e hifema (Dziezyct, 1990).

\section{Facoemulsificação}

Na técnica de facoemulsificaçăo realiza-se incialmente uma incisão muito pequena, de aproximadamente 3 milímctros na córnea. a 1 a 2 milimelros do limbo (Dziezyct, 1990). Após isso, faz-se entāo a capsulectomia parcial, por onde se introduz a peça terminal do aparelho facoemulsificador, que contém uma agulha de titânio de um milímetro de diâmetro revestida por silicone. Quando o aparelho é acionado, a agulha vibra a uma frẹuiência de $40 .(x)$ hertz. Estas vibraçĩes produzem o ulıra-som, que possibilita a fragmentação do córtex e núcleo do cristalino. Esse processo é facilitado com o auxílio de um sistema fechado de aspiração e irrigação que o aparclho facoemulsificador possui ${ }^{1768}$.

Uma lente intra-ocular especialmente fabricada para uso veterinário pode ser implantada entre a cápsula anterior e a posterior do cristalino, para que eventuais diplopias sejam corrigidas e para que os pacientes possam atingir a emetropia sem o cristalino. Muitos trabalhos mostram que a lente de 41 a 42 dioptrias positivas de 6 milímetros, fabricada em polimetil-metracrilato, propicia uma emetropia na maioria dos pacientes caninos que tiveram o cristalino removido inteiramente 3.5 .500 .14 .

A facoemulsificaçāo endocapsular é uma técnica muito segura. no entanto. é necessário cautela para que se evite o contato da ponta do transdutor com a íris ou com a cápsula posterior. Este problema é solucionado quando o cirurgiāo adquire mais prática com 0 aparelho e familiaridade com a técnica (Dziezyc", 1990).
Um antigo problema na facoemulsificação era o dano endotelial da córnea pós-cirúrgico observado em alguns pacientes. Este problema foi contornado com algumas modificações na técnica, uso da irrigação com substâncias viscoelásticas de melhor qualidade e de uma melhor seleção dos pacientes para a cirurgia como advento da microscopia especular da córnea (Neto ${ }^{12}, 1994$ ).

As substâncias viscoelásticas são fluidos mais viscosos que soluçôes fisiológicass utilizadas normalmente. São especialmente fabricados para a cirurgia oftálmica. Quando aplicadas por via intraocular durante a cirurgia, estas substâncias mantêm a estrutura c a pressāo interna do olho de uma maneira mais duradoura do que as soluções não viscoclásticas, impedindo que haja o colapso do globo ocular durante a cirurgia. Alguns autores sugerem ainda que as substâncias viscoelásticas possuem uma funçāo protetora em relaçāo ao endotélio da córnca durante a facoemulsificação (Neto ${ }^{12}$, 1994).

A taxa de sucesso da cirurgia é de aproximadamente $95,0 \%$, não depende da idade do paciente e tende a aumentar à medida que o cirurgiāo adquire maior experiência com o aparelho ${ }^{3511,1213}$.

\section{Vantagens da facoenulsificaçāo}

- Menor incisão da córnca

- Menor risco de deiscência da sutura

- Remoção completa de todo o cristalino

- Maior segurança para o cirurgião

- Menor manipulação das estruturas intra-oculares

- Menor risco de uveíte pós-cirúrgica tardia

- Menor risco de infecção cirúrgica

- Recuperação pús-cirúrgica mais rápida

- Ausência de problemas pós-implante de lente intraocular

- Método mais prático do que as antigas técnicas

Estes dados foram documentados por vários oftalmologistas, tanto na Medicina como na Medicina Veterinária, que utilizam a técnica de facoemulsificação rotineiramente (Neto ${ }^{12}, 1994$ : Nasisse $\left.{ }^{10}, 1995\right)$.

\section{DISCUSSĀO E CONCLUSŌES}

O conhecimento dos parâmetros de classificicação de cataratas é muito importante para o clínico de pequenos animais. 0 acesso a estas informações facilita grandemente a atuação de um especialista em oftalmologia nos casos que the forem referidos, possibilitando uma melhor compreensāo da evoluçāo da opacificação e ajudando uma seleçāo melhor de pacientes para a cirurgia.

As vantagens da técnica de facoemulsificaçāo, quando comparada às outras técnicas cirúrgicas de correçāo da catarata, são empolgantes. No entanto, o que limita a popularização do uso desta técnica entre os oftalmologistas veterinários no Brasil é o fator econômico. $O$ alto custo do aparelho facoemulsificador $e$ do material necessário para a realização da cirurgia bloqueia o rápido progresso da cirurgia oftálmica na Medicina Veterinária brasileira. Conseqüentemente, prejudica um avanço ainda maior da oftalmologia médica, pois a observação dos resultados obtidos nos animais serve de modelo científico excelente para que novas variaçōes das técnicas sejam testadas e aperfeiçoadas. 


\section{SUMMARY}

Cataract means any opacity present in the lens, lens capsule or both. The opacities may vary in size, location, shape and rate of progression. By slit-lamp biomicroscopy it is possible to examine them with precision, determining its exact location and peculiarities, resulting in a safe, accurate diagnosis. Due to its variable origin and appearance, several methods of classification have been used. Classification by aetiology, grade of maturity, location and age of the patients are presented in this review. Surgical removal is the only effective therapy for this disease. Among the surgical techniques available to this day, endocapsular phacoemulsification excells for its better results, despite of its high cost, if compared to classical intra and extra capsular facectomies.

UNITERMS: Cataract; Phacoemulsification; Dogs, Cats.

\section{REFERENCLAS BIBLIOGRÁFICAS}

1-BARROS, P.S.M. Aspectos clínicos da catarata no cảo. Revista da Faculdade de Medicina Veterináría e Zootecnia da Universidade de São Paulo, v.26, n.2, p.199-206, 1989.

2-BARROS, P.S.M. Cirurgia da catarata no căo. Brazllian Journal of Veterinary Research and Animal Science, v.27, n.2, p.199-208, 1990.

3-CARASTRO, S. Treatment of cataract in dog, v.1, n.1, 1993. Veterinary medicine and Surgery, New York. (Intern Circulation).

4-CULLON, R.D.Jr.; CHANG, B. General ophthalmic problems. Acquired cataract. In: The Wills Eye Manual. Office and Emergency Room Diagnosis and Treatment of Eye Disease. 2.ed., Philadelphia, 1994. J.B. Lippincolt, p.425-7.

5-DAVIDSON, M.G.; NASSIE, M.P; JAMIESON, V.E.; ENGLISH, R.V.; OLIVERO, D.K. Phacoemulsification and intraocular lens implantation: a study of surgical results in 182 dogs. Progress in Veterinary and Comparative Ophthalmology, v.1, n.4, p.233-8, 1991.

6-DZIEZYC, J. Cataract surgery current approaches. The Veterinary Clinics of North America. Small Animal Ophthalmology, v.20, n.3, p.737-54, 1990.

7-DZIEZYC, J. Management of cataracts in horses. Compendium on Continuing Education for the Practicing Veterinarian, v.15, n.12, p.1640-1, 1993.

8-ENGLISH, R.V. Disease of the lens and vitreous. In: MORGAN, R.V. Handbook of small animal practicioner, New York, Churchill Livingstone, 1992, p.1093-104.

9-MILLER, T.R.; WHITLEY, R.D.; MEEK, L.A.; GARCIA, G.A.; WILSON, M.C.; RAWLS, B.H.Jr. Phacofragmentation and aspiration for cataract extraction in dogs. Journal of the American Veterinary Medical Association, v.190, n.12, p.1577-80, 1987.

10-NASISSE, M.P. Innovations in cataract surgery. In: BONAGURA, J.D. Kirk's current veterinary therapy XII - Small animal practice, Philadelphia, W.B. Saunders, 1995.

11-NASISSE, M.P.; DAVIDSON, M.G.; JAMIESON, V.E.; ENGLISH, R.V.; OLIVERO, D.K. Phacoemulsification and intraocular lens implaniation: a study of technique in 182 dogs. Progress in Veterinary and Comparative Ophthalmology, v.1, n.4, p.225-32, 1991.

12-NETTO, J.J. Técnica Cirúrgica da Facoemulsificação. In: Iníciando em Facoemulsificaçåo. "Controvérsias em Oftalmologia". VI Congresso Sul- Brasileiro de Oftalmología. Curitiba, 19 a 21 de maio de 1994.

13-NEUMANN, W. Chirurgische behandlung der katarakt beim kleintier. Kleintierpraxis, v.36, n.1, p.17-28. 1991.

14-ROVERSI, G.D.; GIAVINI, E. Damage to the crystalline lens in infants of diabetic mothers: Pathology so far neglected?. Ophthalmologica, v.204, n.4, p.175-8, 1992.

15-RUBIN, L.F. Inherited eye disease in purebred dogs, Maryland, Willians \& Wilkins, 1989, p.2-294.

16-SLATTER, D. Fundamentals of veterinary ophthalmology, Philadelphia, W.B. Saunders, 1990. p. 365-93.

17-STILES, J. Cataracts in a kitten with nutritional secondary hyperparathyroidism. In: Progress in Veterinary and Comparative Ophthalmology. v.1, n.4, p.296-8, 1991.

18-STRANDE, A.; NICOLAISSEN, B. BJERKAS, I. Persistent pupillary membrane and congenital cataract in a litter of English Cocker
Spaniels. In: Journal of Small Animal Practice. v.29, n.4, p.257-60, 1988.

19-WHITLEY, R.D.; MCLAUGHLIN, S.A.; WHITLEY, E.M.; GILGER, B.C. Cataract removal in dogs. In: Veterinary Medicine. Lenexa, Veterinary Medicine Publishing, 1993. p.848-66.
Recebido para publicação: 11/04/95 Aprovado para publicação: 27/03/96 